\title{
Editorial
}

\section{Addressing disparities among children with cerebral palsy: Optimizing enablement, functioning, and participation}

\author{
Deirdre Flanagan $^{\mathrm{a}, *}$, Deborah Gaebler ${ }^{\mathrm{b}}$, Emma-Lorraine B. Bart-Plange $^{\mathrm{a}}$ and Michael E. Msall ${ }^{\mathrm{a}}$ \\ ${ }^{a}$ University of Chicago Comer Children's Hospital, Section of Developmental and Behavioral Pediatrics, Chicago, \\ IL, USA \\ ${ }^{\mathrm{b}}$ Shirley Ryan Abilities LAB, Chicago, IL, USA
}

\begin{abstract}
.
PURPOSE: Recognizing health disparities among children with cerebral palsy (CP) is necessary for understanding potential risk factors for $\mathrm{CP}$ and for implementing early and effective preventative and intervention treatments. However, there is currently little and conflicting evidence regarding the direct impact of contextual factors such as socioeconomic status (SES) for children with CP in the United States. These contextual factors include the complex social determinants of health on prematurity, comprehensive informed obstetric management for minority and vulnerable populations, and cumulative adversity disproportionately experienced by children, by gender, minority status, immigration, poverty, and structural racism.

METHODS: This study presents results from a review of health disparities among children with CP, using registry and population surveillance data from Australia, Canada, Scandinavia, the United Kingdom, Ireland, Turkey, and the United States.

RESULTS: The review confirmed that there are significant health disparities among children with $\mathrm{CP}$, both in terms of prevalence and severity, based on factors such as SES, neighborhood disadvantage, maternal education, gender, and minority status.

CONCLUSION: Strategies need to be implemented in the United States to promote enablement and functioning among children with $\mathrm{CP}$ who face additional health disparities. This requires a greater understanding of population groups at increased risk, comprehensive assessment and care for young children with motor delays, and systematic population counts of children and adults with CP using registries and systems of neurodevelopmental surveillance across health, education, and community rehabilitation. These efforts also require sensitivity to structural and persistent racism, stigma, trauma-informed care, and culturally sensitive community engagement. Additional efforts are also required to improve outcomes over the life course for individuals living a life with CP from a framework of enablement, self-direction, equity and social justice.
\end{abstract}

Keywords: Cerebral palsy, early detection, enablement, registries, functioning, health disparities

${ }^{*}$ Corresponding author: Michael E. Msall, University of Chicago Comer Children's Hospital and JP Kennedy Research Center, Section of Developmental and Behavioral Pediatrics, 950 East 61st Street, SSC Room 207, Chicago Illinois 60637, USA. Tel.: +1 7737023095 Fax: +1 773702 0208; E-mail: mmsall@ peds.bsd.uchicago.edu.

\section{Understanding population data about children with cerebral palsy}

Cerebral palsy $(\mathrm{CP})$ describes a group of permanent disorders of the development of movement and posture, causing activity limitation, and which are attributed to nonprogressive disturbances occurring in the developing fetal or infant brain [1]. This brain dysfunction impacts cortical and subcortical control of movement and 
neurodevelopmental pathways underlying select motor control, visual and auditory sensation and perception, cognition, communication, behavior and epilepsy, and musculoskeletal integrity [2].

Pilot population studies have demonstrated the prevalence of $\mathrm{CP}$ and related developmental disabilities among children in the United States (US) using survey questionnaires. According to the 2011-2013 National Health Interview Survey (NHIS), CP prevalence was 2.9 per 1000 children based on parent report among children aged 2-17 years [3]. In order to better estimate $\mathrm{CP}$ prevalence and in turn more effectively target health, habilitative, and community rehabilitative services, it is important to understand how CP prevalence is affected by factors such as race, gender, socioeconomic status (SES), and maternal education.

There is currently little and conflicting evidence regarding the direct impact of these factors on children with CP in the US because there are no systematic population counts across preschool, middle childhood, adolescence and adult developmental epochs. However, there seem to be clear indicators that such factors can affect the prevalence of developmental disabilities. Community indicators of their impact include early intervention services, specialty health services, rehabilitation services at home and school, equipment, community caregiving supports, access to spasticity management teams, educational opportunities, vocational training, and community living. According to the 2009-2017 National Health Interview Survey (NHIS), there were significant increases in the prevalence of any developmental disability (including Autism Spectrum Disorder, CP, intellectual disability, and vision, hearing, and developmental delays) from 2009-2011 to 20152017. During this period in the US, boys, non-Hispanic white and Hispanic children as well as children with less educated mothers experienced increased rates of neurodevelopmental disabilities [4]. Additionally, estimates from the 1997-2003 NHIS indicate that children with intellectual and related developmental disabilities were $8 \%$ more likely than children without these diagnoses to reside in poverty and $10 \%$ less likely to be residing in a 2-parent home [5]. Indeed, even for children without developmental disabilities, maternal SES is considered a strong predictor of child health status, educational success, and adolescent well-being [6]. Not only has poverty been found to be linked to specific perinatal and early childhood health outcomes such as low birth weight and failure to thrive (FTT), but indicators of SES have also been found to significantly and strongly relate to negative long-term health and edu- cational outcomes. These consequences include those relating to kindergarten readiness and educational trajectories of cognition, behavior regulation, literacy and numeracy [7]. Such disparities in long-term outcomes may also reflect socioeconomic disparities in access to appropriate health and community resources during early childhood, middle childhood, adolescence, and young adulthood. These management services require a family centered medical home that enables functioning and participation and involves primary care physicians, medical and rehabilitation specialists, therapists, educators, counselors, and mentors [36].

Additional emphasis is required in addressing health disparities for individuals who are Black, Hispanic, and Native American with particular attention to structural racism. Importantly, there is a link of SES to systemic racism in that past and current laws and policies have prevented these groups from amassing wealth, being represented in the political sphere, and living in areas with environmental safety and adequate resources [37]. These resources include appropriately funded schools, accessible health services, and diversity in health, education and community workforces. Environmental safety includes limited exposure to environmental toxins based on where home or other structures like highways are built.

Recent data from Australia, Canada, Sweden, Denmark, Norway, the United Kingdom (UK), Ireland, and Turkey have suggested that SES and neighborhood adversity can affect the prevalence of CP. Again, racial minorities in other Western nations experience disparities based on SES that are compounded by racist imperialist roots. For example, the UK had a historically rigid class structure and restricted opportunities for religious and racial/ethnic minorities [31-33].

SES is affected not only by that class structure history, but also by the ways that religious and racial/ethnic minorities in that nation have been systemically exploited and oppressed by the ruling class [34,35]. Specifically, policies that have disproportionately privileged affluent, white Anglo-Saxon, Protestant individuals without social justice require ongoing strategies for equity [38].

Table 1 highlights some of these population data.

In a UK population study, the prevalence of $\mathrm{CP}$ in the most deprived quintile (3.33 per 1000 births) was 1.5-1.6 times higher than the prevalence in the most affluent quintile (2.08 per 1000 births) [8]. Such a strong socioeconomic gradient indicates that if the whole population had the rate of $\mathrm{CP}$ of that most affluent quintile, up to $17 \%$ of CP cases could be 'preventable' [8]. Im- 
Table 1

Model CP and disparities population studies: SES, maternal education and neighborhood deprivation

\begin{tabular}{|c|c|c|}
\hline $\begin{array}{l}\text { Location (First } \\
\text { Author) }\end{array}$ & Cohort & Results \\
\hline $\begin{array}{l}\text { Australia } \\
\text { (Woolfenden) }\end{array}$ & $\begin{array}{l}\text { - } 1993-2009 \\
-N=7,2415 \text {-year-old children with CP }\end{array}$ & $\begin{array}{l}\text { - Neighborhood social disadvantage increases risk of severe CP } \\
\text { - Risk Ratio } 1.2 \text { increase GMFCS } 4 \text { and } 5 \text { CP } \\
\text { - Risk Ratio } 1.4 \text { and IQ }<50 \\
\text { - Risk Ratio } 1.2 \text { severe comorbidities (epilepsy, blind, deaf, CD) }\end{array}$ \\
\hline UK (Sundrum) & $\begin{array}{l}-1982-1997 \\
-N=295,760 \text { total } \\
-N=293 \text { individuals with CP }\end{array}$ & $\begin{array}{l}\text { - Low SES is a risk factor for CP } \\
\text { - aOR of } 1.55 \text { for area-based SES }\end{array}$ \\
\hline Sweden (Hjern) & $\begin{array}{l}-1987-1993 \\
-N=805,543 \text { total } \\
-N=1,437 \text { individuals with } \mathrm{CP}\end{array}$ & $\begin{array}{l}\text { - Low SES increases OR of } 1.49 \text { for CP } \\
\text { - Reduced to OR of } 1.36 \text { after adjusting for perinatal variables }\end{array}$ \\
\hline Canada (Oskoui) & $\begin{array}{l}\text { - } 1999-2010 \\
-N=499 \text { children with CP }\end{array}$ & - Increased GMFCS 4 and 5 for preterm OR 4.2, term OR 1.5 \\
\hline Ireland (Dowding) & $\begin{array}{l}-1976-1981 \\
-N=150,189 \text { total } \\
-N=289 \text { individuals with } \mathrm{CP}\end{array}$ & - Low SES increases the risk of diplegic or hemiplegic CP \\
\hline $\begin{array}{l}\text { Scandinavia } \\
\text { (Forthun) }\end{array}$ & $\begin{array}{l}\text { - } 1.3 \text { million children in Denmark (1981- } \\
2007) \\
-2.4 \text { million children in Norway (1967- } \\
2007)\end{array}$ & $\begin{array}{l}\text { - High parental education provided risk reduction (RR } 0.58 \text {, CI } 0.58 \text { - } \\
0.63 \text { ) } \\
\text { - Women with partners had a reduced risk of having baby with CP (RR } \\
0.79, \text { CI } 0.74-0.85)\end{array}$ \\
\hline US (Durkin) & $\begin{array}{l}-2002-2008 \\
-N=458,027 \text { total } \\
-N=1,570 \text { 8-year-old children with CP }\end{array}$ & $\begin{array}{l}\text { - Low SES increases risk of CP } \\
\text { - Risk of spastic CP increased in black children as compared to white } \\
\text { children (RR 1.52, CI 1.3-1.7) }\end{array}$ \\
\hline
\end{tabular}

portantly, it is recognized in these registries that aboriginal and Torres Island and Inuit populations, refugees, and racial and religious minorities experience ongoing barriers to accessing basic housing, education, health care, and community supports.

In contrast to Scandinavia, Australia, and Canada, the US has no comprehensive population registry of young children, school age children, adolescents or adults with CP. There have been attempts to remedy this for children with extreme and very preterm birth and infants with neonatal encephalopathy, and through registries of children with malformations involving the central nervous system, as well as cardiac, gastrointestinal, urological and other organ systems. Further attempts have included expanding the Centers for Disease Control (CDC) Autism and Developmental Disabilities Monitoring (ADDM) surveillance network to also include $\mathrm{CP}$ prevalence at age 8 in a defined geographic region using multi-source medical, education, and community records. Currently, these ADDM + CP sites have been limited to metropolitan Atlanta, Wisconsin, and Alabama.

In the US, CP prevalence has consistently been found to be significantly higher in non-Hispanic black children than in non-Hispanic white children [9-11]. One study using the ADDM Network found that the risk of spastic CP for black children was more than $50 \%$ higher than it is for white children [9]. Interestingly, this increased risk persisted even after adjusting for SES; this suggests that the effects of SES do not fully explain the increased risk of CP in black children [9]. Also, the ADDM Network was not designed to address underlying factors of structural racism and inequality.

It is important to note that race in and of itself is not the reason for these disparities. The social construction of race is the foundation for racism, so although results are discussed in terms of disparities for certain groups, the risk factor is not race. Rather, race is being used as a proxy for the experience of racism on a structural level. In both the US and other Western nations, these structural racial inequalities have roots in imperialism, colonization, and chattel slavery.

The ADDM + CP epidemiological study supported previous studies which indicated that these disparities by race were partially explained by higher rates of preterm birth, white matter vulnerability, and low birthweight status among black infants $[9,11]$. It is beyond the scope of this paper to fully explain racial disparities and their mechanisms underlying prematurity, low birthweight, maternal morbidity and mortality, and infant mortality. However systematic strategies for addressing the impact of structural and persistent racism have been brought to the attention of citizens, policy makers, and public health professionals [23-25].

Additionally, studies performed in the US have found $\mathrm{CP}$ risk to be significantly and consistently higher in 
males than females $[9,10]$. Data from the ADDM Network also found that low SES was associated with a $67 \%$ increased risk of CP overall and a $93 \%$ increased risk of spastic $\mathrm{CP}$ when compared to risk levels of high SES [9]. These gender specific disparities require more attention to complex mechanisms of brain vulnerability and plasticity across key epochs.

In addition to understanding the prevalence of $\mathrm{CP}$, it is also important to understand whether factors such as race, gender, SES, and maternal education can affect the severity of CP among children in the US. While it can be challenging to quantitatively assess the functioning of children with CP, the Gross Motor Function Classification System (GMFCS), published in 1997 and utilized by all current $\mathrm{CP}$ registries and surveillance programs throughout the world, provides a useful tool for monitoring the gross motor functioning of individuals with $\mathrm{CP}$ over time [12]. Additional tools for assessing the impact of $\mathrm{CP}$ on an individual's functioning and participation include the Manual Ability Classification System (MACS), the Communication Functional Classification System (CFCS), the Eating and Drinking Ability Classification System (EDACS), and the Visual Functioning Classification System (VFCS) [17-20]. These additional classification systems provide important descriptors of children's fine motor, oral motor (chewing and swallowing), communication and visual functioning.

The GMFCS has been utilized in a population study performed in Canada in order to examine the impact of both individual-level and area-level socioeconomic determinants on the severity of CP in children. This study did observe a socioeconomic gradient in mobility, above and beyond differences in maternal and perinatal factors [6]. Children in the most deprived areas were more likely than children in the least deprived areas to have non-ambulatory gross motor function, especially if they were preterm. In addition, children with mothers who did not attain a high school diploma were more likely to have a non-ambulatory status on GMFCS ratings (i.e., GMFCS level IV or V) [6]. These findings suggest that contextual factors regarding SES and maternal education at both the individual and community level can affect the severity of $\mathrm{CP}$ in children.

Additional studies from Ireland, Turkey, and Western Australia support the findings that SES factors are associated with the prevalence and severity of $\mathrm{CP}$ in children. In Ireland, a study found a clear, rising trend in the presence of hemiplegia and diplegia with decreasing social class status; in fact, such a gradient was found only in severe cases of CP [13]. Although a Turkish study of 41,861 children did not find an increased risk for diplegia in children with a low SES, it did find increased adverse perinatal factors contributing to $\mathrm{CP}$ in children with social disadvantage [14]. Finally, an Australian study performed in 2019 determined that certain groups of individuals who were born preterm (including males, those with Aboriginal maternal ethnicity, and those with low SES) were at a higher risk of developing disabilities such as $\mathrm{CP}$, intellectual disability and autism during childhood [15]. Since the prevalence of $\mathrm{CP}$ is strongly associated with preterm birth, these results have significant implications for the ways in which contextual factors such as structural racism, gender, and SES could affect the prevalence of CP.

The most robust data for evaluating equity and enablement across populations comes from the Australian Cerebral Palsy Register. This network of investigators found a socioeconomic gradient relating individual and area level factors to severity of functioning in children with CP. Specifically, it found that adolescent motherhood and maternal minority ethnicity were associated with increased limitations in functioning in mobility, manipulation, communication and cognition, as well as the presence of severe comorbidities such as epilepsy and auditory and visual impairments [16]. This study also found that when such individual-level factors were not present, decreasing neighborhood SES status was associated with increased severity of CP functional limitations. These Australian registry data support the Canadian registry data regarding the interaction between individual- and area-level contextual factors $[6,16]$. However, while the Canadian study found socioeconomic gradient present only in infants who were born preterm, the Australian registries found socioeconomic gradients present for all, whether preterm or term $[6,16]$.

While many studies seem to indicate that $\mathrm{CP}$ is more prevalent and also more severe among certain groups in the US - including males, non-Hispanic black children, children who live in households and neighborhoods with lower SES, and children with mothers who have lower educational attainment - further studies are needed to explore the direct impact of these contextual factors on the life-course outcomes of children with CP [26,27]. Such studies are necessary for better understanding significant risk factors for CP and for providing earlier, comprehensive, precise, and more effective treatments for high-risk vulnerable populations $[28,29]$. These risk factors are a call to action to more systematically address health disparities in the US with explicit attention to community and population based interventions that have an impact on social determinants of health and address transgenerational impacts of structural racism [30]. 


\section{Strategies to lessen disparities and promote enablement and equity}

What is required to begin to address such health disparities? First, there must be increased recognition that there are four major risk groups for CP. These include: all degrees of prematurity; neonates with encephalopathy or seizures; infants with malformations (cardiac, GI, GU); and most importantly, and unknown. In the last category there is increased recognition of the value of both placenta investigation and genetic investigation.

In current systems of care, there is fragmentation in appropriately diagnosing $\mathrm{CP}$ in highest risk children before 6 months. This can best be addressed by recognizing high risk indicators (e.g., IVH 3-4, periventricular leukomalacia [PVL], neonatal seizures) and creating collaborative systems of NICU surveillance, early detection, and linkage to habilitation. Embedded in high risk NICU surveillance are the disparities impacting young children's health and development that include social determinants of health, adverse child health experiences, and the structural racism underlying concentrated economic poverty with housing insecurity, food insecurity, limited employment, and limited community resources. More informed, culturally sensitive, proactive basic and human capital resources are required for these vulnerable children and families.

The second strategy is to promote the comprehensive assessment of children with motor delays across primary care, subspeciality care, and early intervention care. This requires red flags for health professionals and families through close attention to silent impairments (e.g., vision, hearing, cardiac, gastrointestinal, urological), and prompt access to regional multi-disciplinary networks of excellence. Navigators, care coordinators, and informed case managers are needed to partner with diverse families, problem-solve safety net inequities in basic needs, and address transportation, childcare, elder care, and family work complexity.

Third, we must accurately and consistently focus our efforts on a population level on early detection, management pathways, and the impact on children's medical, developmental, and adaptive skills. This requires several action steps including the uniform usage of multidimensional neurodevelopmental evaluations; collaboration with primary care physicians, therapists, and early intervention specialists in order to optimize neuroplasticity in early childhood; and changing the framework of intervention to activities that can be implemented by parents during daily routines with informed therapists as coaches. It is in this context that play and routines of the day become activity-based habilitation opportunities. It is these activities of explicitly meeting the needs of diverse families, addressing stigma, and advocating for child participation and family well-being that we can better understand if our support systems are culturally and family sensitive and able to promote social justice. This requires equity for basic housing, employment, and health services as well as ensuring that services for vulnerable children and families are audited and transparent so that children residing in neighborhoods formed by structural racism are not given fewer supports and opportunities than those residing in resourced communities.

Over two decades ago, one of us (MEM) attended the Australasian Academy of Physical and Developmental Medicine in Perth. This interdisciplinary conference included neurodevelopmental pediatricians, pediatric physiatrists, physical therapists, occupational therapists, speech therapists, orthopedic surgeons, and epidemiologists. Several equity observations were highlighted: why does a senior citizen access rehabilitation and equipment in the first month of stroke onset, while after critical illnesses requiring neonatal neurological or cardiac intensive care, children with $\mathrm{CP}$ wait two years for an informed diagnosis, three years for mobility devices and informed rehabilitation management, five years for a communication device, 10 years for recreation access, and 16 years for peer supports and mentoring? Why does a child of Aboriginal ancestry not have access to comprehensive medical services for epilepsy, spasticity, or hip dysplasia? Why is there limited middle childhood participation in recreation and community experiences that promote after school friendships and decrease isolation, bullying, and stigma? This experience at the conference highlighted the value of systematically counting in registries the complexity of CP across health, education and community support systems of care. If we can count the demographics, medical and rehabilitation management, and community supports required by elder adults with stroke, why can we not count children with CP?

In the US, where there is increasing recognition of living a life with CP (Cerebral Palsy Foundation: https:// www.yourCPF.org), we can go beyond fixing what we do not fully understand and systematically count, audit and improve population outcomes. Our focus can be on precisely optimizing trajectories of functioning, participation, and caregiver well-being [21,22]. That is our task as we aspire to integrated, enabled and equitable systems of population health for all children and adults with CP after the COVID-19 pandemic. 


\section{Conflict of interest}

Dr. Msall is supported in part by HRSA/MCHB T73 MC11047 Leadership Education in Neurodevelopmental and Related Disorders Training Program (LEND) and NIH/NICHD UG3OD023348 ELGAN 3: Environment, Epigenetics, Neurodevelopment \& Health of Extremely Preterm Children, and is an unpaid board member of the Pathways Medical Roundtable, a not-forprofit organization that promotes partnerships between families and rehabilitation professionals for young children with neuromotor delays.

The other authors have no conflicts of interest to declare.

\section{References}

[1] Graham HK, Rosenbaum P, Paneth N, Dan B, Lin JP, Damiano DL, et al. Cerebral palsy. Nat Rev Dis Primers. 2016; 2: 15082. doi: 10.1038/nrdp.2015.82.

[2] Wilamasundera N, Stevenson VL. Cerebral palsy. Pract Neurol. 2016; 16(3): 184-194. doi: 10.1136/practneurol-2015-001 184.

[3] Maenner MJ, Blumberg SJ, Kogan MD, Christensen D, Yeargin-Allsopp M, Schieve LA. Prevalence of cerebral palsy and intellectual disability among children identified in two U.S. National Surveys, 2011-2013. Ann Epidemiol. 2016; 26(3): 222-226. doi: 10.1016/j.annepidem.2016.01.001.

[4] Zablotsky B, Black LI, Maenner MJ, Schieve LA, Danielson ML, Bitsko RH, et al. Prevalence and trends of developmenta disabilities among children in the United States: 2009-2017. Pediatrics. 2019; 144(4): e20190811. doi: 10.1542/peds.20190811.

[5] Hogan DP, Msall ME, Drew JAR. The developmental epidemiology of mental retardation and developmental disabilities. in: Developmental Epidemiology of Mental Retardation and Developmental Disabilities, Urbano R, Hodapp R, eds, 2006; 213-245.

[6] Oskoui M, Messerlian C, Blair A, Gamache P, Shevell M. Variation in cerebral palsy profile by socio-economic status. Dev Med Child Neurol. 2016; 58(2): 160-166. doi: 10.1111/ dmen. 12808 .

[7] Msall ME, Tremont MR. Measuring functional outcomes after prematurity: Developmental impact of very low birth weight and extremely low birth weight status on childhood disability. Ment Retard Dev Disabil Res Rev. 2002; 8(4): 258-272. doi: 10.1002/mrdd.10046.

[8] Dolk H, Pattenden D, Johnson A. Cerebral palsy, low birthweight and socio-economic deprivation: Inequalities in a major cause of childhood disability. Paediatr Perinat Epidemiol. 2001; 15(4): 359-363. doi: 10.1046/j.1365-3016.2001.00351.x.

[9] Durkin MS, Maenner MJ, Benedict RE, Van Naarden Braun K, Christensen D, Kirby RS, et al. The role of socio-economic status and perinatal factors in racial disparities in the risk of cerebral palsy. Dev Med Child Neurol. 2015; 57(9): 835-843. doi: 10.1111/dmen.12746.

[10] Van Naarden Braun K, Christensen D, Doernberg N, Schieve $\mathrm{L}$, Rice $\mathrm{C}$, Wiggins $\mathrm{L}$, et al. Trends in the prevalence of autism spectrum disorder, cerebral palsy, hearing loss, intellectual disability, and vision impairment, metropolitan Atlanta, 19912010. PLoS One. 2015 Apr 29; 10(4): e0124120. doi: 10.1371/ journal.pone.0124120.

[11] Wu YW, Xing G, Fuentes-Afflick E, Danielson B, Smith LH, Gilbert WM. Racial, ethnic, and socioeconomic disparities in the prevalence of cerebral palsy. Pediatrics. 2011; 127(3): e674-81. doi: 10.1542/peds.2010-1656.

[12] Goldsmith S, McIntyre S, Smithers-Sheedy H, Blair E, Cans C, Watson L, et al. An international survey of cerebral palsy registers and surveillance systems. Dev Med Child Neurol. 2016; 58(Suppl 2): 11-17. doi: 10.1111/dmcn.12999.

[13] Dowding VM, Barry C. Cerebral palsy: Social class differences in prevalence in relation to birthweight and severity of disability. J Epidemiol Community Health. 1990; 44(3): 191-195. doi: 10.1136/jech.44.3.191.

[14] Serdaroglu A, Cansu A, Ozkan S, Tezcan S. Prevalence of cerebral palsy in Turkish children between the ages of 2 and 16 years. Dev Med Child Neurol. 2006; 48(6): 413-416. doi: 10.1017/S0012162206000910.

[15] Bourke J, Wong K, Srinivasjois R, Pereira G, Shepherd CCJ, White SW, et al. Predicting long-term survival without major disability for infants born preterm. J Pediatr. 2019; 215: 90-97. doi: 10.1016/j.jpeds.2019.07.056.

[16] Woolfenden S, Galea C, Smithers-Sheedy H, Blair E, Mcintyre $\mathrm{S}$, Reid S, et al. Impact of social disadvantage on cerebral palsy severity. Dev Med Child Neurol. 2019; 61(5): 586-592. doi: 10.1111/dmcn.14026.

[17] Baranello G, Signorini S, Tinelli F, Guzzetta A, Pagliano E, Rossi A, et al. Visual function classification system for children with cerebral palsy: Development and validation. Dev Med Child Neurol. 2020; 62(1): 104-110. doi: 10.1111/dmcn. 14270.

[18] Eliasson AC, Krumlinde-Sundholm L, Rösblad B, Beckung E, Arner M, Ohrvall AM, et al. The manual ability classification system (MACS) for children with cerebral palsy: Scale development and evidence of validity and reliability. Dev Med Child Neurol. 2006; 48(7): 549-554. doi: 10.1017/S001216 2206001162.

[19] Hidecker MJC, Paneth N, Rosenbaum PL, Kent RD, Lillie $\mathrm{J}$, Eulenberg JB, et al. Developing and validating the communication function classification system for individuals with cerebral palsy. Dev Med Child Neurol. 2011; 53(8): 704-710. doi: 10.1111/j.1469-8749.2011.03996.x.

[20] Sellers D, Mandy A, Pennington L, Hankins M, Morris C. Development and reliability of a system to classify the eating and drinking ability of people with cerebral palsy. Dev Med Child Neurol. 2014; 56(3): 245-251. doi: 10.1111/dmcn.12352.

[21] Rosenbaum P, Gorter JW. The 'F-words' in childhood disability: I swear this is how we should think! Child Care Health Dev. 2012; 38(4): 457-463. doi: 10.1111/j.1365-2214.2011.01338.x

[22] Tajik-Parvinchi D, Davis A, Roth S, Rosenbaum P, Hopmans SN, Dudin A, et al. Functional connectivity and quality of life in young adults with cerebral palsy: A feasibility study. BMC Neurol. 23 Oct 2020; 20(1): 388. doi: 10.1186/s12883-02001950-7.

[23] Gadson A, Akpovi E, Mehta PK. Exploring the social determinants of racial/ethnic disparities in prenatal care utilization and maternal outcome. Semin Perinatol. 2017; 41(5): 308-317. doi: 10.1053/j.semperi.2017.04.008.

[24] Cox RG, Zhang L, Zotti ME, Graham J. Prenatal care utilization in Mississippi: Racial disparities and implications for unfavorable birth outcomes. Matern Child Health J. 2011; 15(7): 931-942. doi: 10.1007/s 10995-009-0542-6. 
[25] Gopal DP, Rao M. Playing hide and seek with structural racism. BMJ. 2021; 373: n988. doi: 10.1136/bmj.n988.

[26] Berg KL, Shiu CS, Feinstein RT, Acharya K, MeDrano J, Msall ME. Children with developmental disabilities experience higher levels of adversity. Res Dev Disabil. 2019; 89: 105-113. doi: 10.1016/j.ridd.2019.03.011.

[27] Carter FA, Msall ME. Health disparities and child development after prematurity. Pediatr Ann. 2017; 46(10): e360-e364. doi: 10.3928/19382359-20170919-02.

[28] Acharya K, Meza R, Msall ME. Disparities in life course outcomes for transition-aged youth with disabilities. Pediatr Ann. 1 Oct 2017; 46(10): e371-e376. doi: 10.3928/1938235920170918-01

[29] Frisch D, Msall ME. Health, functioning, and participation of adolescents and adults with cerebral palsy: A review of outcomes research. Dev Disabil Res Rev. 2013; 18(1): 84-94. doi: $10.1002 /$ ddrr.1131.

[30] Williams DR, Lawrence JA, Davis BA. Racism and health: Evidence and needed research. Annu Rev Public Health. 2019 Apr 1; 40: 105-125. doi: 10.1146/annurev-publhealth-040218043750.

[31] Phillips D, Karn V. Racial segregation in britain: Patterns, processes, and policy approaches. in: Urban Housing Segregation of Minorities in Western Europe and the United States. Huttman ED, ed., Durham, NC: Duke University Press. 1991 63-91. ISBN 978-0822310600.

[32] Bécares L, Nazroo J, Jackson J, Heuvelman H. Ethnic density effects on health and experienced racism among Caribbean people in the US and England: A cross-national comparison. Soc Sci Med. 2012; 75(12): 2107-2115. doi: 10.1016/j. socscimed.2012.03.046.

[33] Gardiner T, Abraham S, Clymer O, Rao M, Gnani S. Racial and ethnic health disparities in healthcare settings. BMJ. 2021; 372: n605. doi: 10.1136/bmj.n605.

[34] Malawa Z, Gaarde J, Spellen S. Racism as a Root Cause Approach: A New Framework. Pediatrics. 2021; 147(1): E20200 15602. doi: 10.1542/peds.2020-015602.

[35] Thomas SB, Quinn SC, Butler J, Fryer CS, Garza MA. Toward a fourth generation of disparities research to achieve health equity. Annu Rev Public Health. 2011; 32: 399-416. doi: 10.1146/annurev-publhealth-031210-101136.
[36] Laraque D, Sia CCJ. Health care reform and the opportunity to implement a family-centered medical home for children. JAMA. 2010; 303(23): 2407-2408. doi: 10.1001/jama. 2010.809

[37] Shonkoff JP, Slopen N, Williams DR. Early childhood adversity, toxic stress, and the impacts of racism on the foundations of health. Annu Rev Public Health. 2021; 42: 115-134. doi: 10.1146/annurev-publhealth-090419-101940.

[38] Riley AR. Advancing the study of health inequality: Fundamental causes as systems of exposure. SSM Popul Health 2020; 10: 100555. doi: 10.1016/j.ssmph.2020.100555.

[39] Woolfenden S, Galea C, Smithers-Sheedy H, Blair E, Mcintyre S, Reid S, Delacy M, Badawi N, Australian Cerebral Palsy Register Group, CP Quest. Impact of social disadvantage on cerebral palsy severity. Developmental Medicine \& Child Neurology. 2019; 61(5): 586-592.

[40] Sundrum R, Logan S, Wallace A, Spencer N. Cerebral palsy and socioeconomic status: A retrospective cohort study. Archives of Disease in Childhood. 2005; 90(1): 15-18.

[41] Hjern A, Thorngren-Jerneck K. Perinatal complications and socio-economic differences in cerebral palsy in Sweden - a national cohort study. BMC Pediatrics. 2008; 8(1): 1-7.

[42] Oskoui M, Messerlian C, Blair A, Gamache P, Shevell M. Variation in cerebral palsy profile by socio-economic status. Developmental Medicine \& Child Neurology. 2016; 58(2): 160-166.

[43] Dowding VM, Barry C. Cerebral palsy: Social class differences in prevalence in relation to birthweight and severity of disability. Journal of Epidemiology \& Community Health. 1990; 44(3): 191-195.

[44] Forthun I, Strandberg-Larsen K, Wilcox AJ, Moster D, Petersen TG, Vik T, Lie RT, Uldall P, Tollånes MC. Parental socioeconomic status and risk of cerebral palsy in the child: Evidence from two Nordic population-based cohorts. International Journal of Epidemiology. 2018; 47(4): 1298-1306.

[45] Durkin MS, Maenner MJ, Benedict RE, Van Naarden Braun K, Christensen D, Kirby RS, Wingate M, Yeargin-Allsopp $\mathrm{M}$. The role of socio-economic status and perinatal factors in racial disparities in the risk of cerebral palsy. Developmental Medicine \& Child Neurology. 2015; 57(9): 835-843. 